\author{
(С) Э.А. Бондарева*, Л.В. Задорожная, И.А. Хомякова
}

ФГБОУ ВО «Московский государственный университет имени М.В. Ломоносова», Москва, Россия

Обоснование. Скорость накопления жира индивидуальна для каждого человека и определяется взаимодействием генетических и средовых факторов. Одним из наиболее изученных молекулярно-генетических маркеров, ассоциированных с ожирением, является полиморфизм гена FTO (T/A, rs9939609).

Цель. Изучение ассоциаций Т/А-полиморфизма гена FTO с количеством жира и его топографией в группе русских мужчин в зависимости от возраста и специфики образа жизни.

Mетоды. Было проведено комплексное антропогенетическое обследование 205 условно здоровых этнических русских мужчин в возрасте от 17 до 52 лет, проживающих в г. Москве. Источником геномной ДНК для генотипирования послужили образцы буккального эпителия. Астрометрические измерения включали калиперометрию и оценку состава тела при помощи биоимпедансометрии.

Результаты. Частоты встречаемости генотипов в обследованной выборке составили: FTO*TT - 14\%, FTO*AT - 52,6\%, $F T{ }^{*} A A-33,4 \%\left(x_{\text {нw }}^{2}=1,65 ; \mathrm{p}=0,193\right)$. Показаны ассоциации А-аллеля гена FTO с предрасположенностью к накоплению жира и его абдоминальной топографией.

Заключение. Среди различных модификаций образа жизни только наличие регулярных физических нагрузок средней и высокой интенсивности нивелировало генетически обусловленную склонность к ожирению.

КЛЮЧЕВЫЕ СЛОВА: FТО; накопление жира; абдоминальное ожирение; мужчины; образ жизни.

\title{
T/A POLYMORPHISM OF THE FTO GENE AND LIFESTYLE ARE ASSOCIATED WITH FAT ACCUMULATION IN DIFFERENT AGE GROUPS OF MEN
}

(c) Elvira A. Bondareva*, Ludmila V. Zadorozhnaya, Irina A. Khomyakova

Lomonosov Moscow State University, Moscow, Russia

BACKGROUND: Adiposity development and its complications are determined by lifestyle, genetic mechanisms and their interactions. Among the obesity-related genes, polymorphisms in the fat mass and obesity associated (FTO) gene are strongly associated with body fat estimates in different populations.

AIMS: to examine the association between the FTO polymorphism (T/A, rs9939609) and fat accumulation in adult russian males.

MATERIALS AND METHODS: The study engaged 205 participants; the age ranged from 17 to 52 years. Samples of buccal smears were collected and genomic DNA was isolated for T/A polymorphism genotyping. Anthropometric measurements were conducted with caliperometry and body composition was estimated by bioimpedance analysis.

RESULTS: Genotype frequencies in the whole studied sample were as follows FTO*TT 14\%, FTO*AT 52,6\%, FTO*AA 33,4\% $\left(X_{H W}^{2}=1,65 p=0,193\right)$. The minor A allele was significantly associated with increased fat accumulation and abdominal adiposity. CONCLUSIONS: Among different lifestyle modifications regular and consistent programmes of exercise are most efficient strategy to reduce abdominal fat deposits significantly, independent of FTO genotype.

KEYWORDS: FTO; fat accumulation; abdominal obesity; males; life style.

\section{ОБОСНОВАНИЕ}

Распространение ожирения в современном мире достигло масштаба пандемии [1]. Избыточный вес и ожирение провоцируют развитие множества тяжелых заболеваний, которые заканчиваются инвалидизацией или смертью пациентов [1, 2]. На индивидуальную предрасположенность к набору веса и скорость данного процесса влияет взаимодействие эндогенных (генетических) и экзогенных (факторов окружающей среды) факторов [3-5]. Среди большого числа молекулярно-генетических маркеров, ассоциированных с ожирением, ген FTO (fat mass and obesity-associated) является одним первых и наиболее широко изученных. Убедительно доказаны ассоциации А-аллеля в первом интроне FTO (T/A, rs9939609) с предрасположенностью к накоплению жира и риском развития ожирения, а также диабета 2 типа $[3,4]$. Несмотря на активное изучение ассоциаций FTO со склонностью к ожирению в контексте особенностей образа жизни и диеты, возраста, пола, этно-расовой принадлежности, и прочих факторов, влияние Т/А-замены на количество жира и его топографию в российской популяции остается малоизученным. 


\section{ЦЕЛЬ}

Целью работы является изучение ассоциаций Т/Аполиморфизма гена FTO с количеством жира и его топографией в группе русских мужчин в зависимости от возраста и специфики образа жизни.

\section{МЕТОДЫ}

Былопроведено комплексноеантропогенетическое обследование 205 условно здоровых русских мужчин в возрасте от 17 до 52 лет. Программа антропометрического обследования включала 39 измерительных признаков: 18 скелетных размеров, 10 обхватов, 11 жировых складок [6], определение состава тела при помощи биоимпедансного анализатора АBC-01 «МЕДАСС» (НТЦ «Медасс», Россия) [7]. Индекс массы тела (ИМТ) рассчитывали по формуле I=W/L2, где I значение индекса; W - вес тела, кг; L - длина тела, м. У всех обследованных добровольцев были собраны образцы буккального эпителия при помощи одноразовых стерильных зондов (Nuova Aptaca, Италия), далее была выделена геномная ДНК, и на базе ООО «Лаборатория Литех» (г. Москва, Россия) было проведено генотипирование по полиморфному локусу гена FTO (rs9939609, Т/A). Также было проведено анкетирование, которое позволило зафиксировать особенности образа жизни и питания, количество и характер физических нагрузок, а также социально-экономической статус обследованных.

\section{Дизайн исследования}

Было проведено обсервационное одноцентровое поперечное исследование.

\section{Анализ в подгруппах}

Обследованная выборка была разделена на три подгруппы согласно схеме возрастной периодизации онтогенеза человека, принятой на VII Всесоюзной конференции по проблемам возрастной морфологии, физиологии и биохимии АПН СССР (Москва, 1965). 94 человека вошли в подгруппу юношей (17-21 год), 70 человек представляют I зрелый возраст (22-35 лет) и 41 человек - II зрелый возраст (36-60 лет). Анализ анкетных данных, отражающих особенности образа жизни обследованных, позволил выделить несколько подгрупп среди добровольцев | и || зрелого возраста: 1. вегетарианцы (49 человек) добровольцы, которые исключили потребление продуктов питания животного происхождения; 2. спортсмены (42 человека) - любители и профессионалы, которые регулярно занимаются спортом (не менее 3 раз в неделю), а также имеют спортивное звание; 3. «контроль» (26 человек) - добровольцы, не имеющие ограничений в питании и не занимающиеся спортом регулярно.

\section{Этическая экспертиза}

Все материалы комплексного обследования, анализируемые в статье, собраны с соблюдением правил биоэтики (экспертное заключение Комиссии МГУ по биоэтике, протокол № 91-о от 24.05.2018). Добровольцы были осведомлены о целях исследования и дали свои письменные информированные согласия. Данные обследованных были деперсонифицированы и анализировались в обезличенной форме.
Статистический анализ

Статистическая обработка полученных данных проводилась с использованием пакета прикладных программ Statistica 8.0 (StatSoft, США). Для оценки достоверности различий в распределениях генотипов использовали непараметрический критерий $\chi 2$. Для проверки соответствия распределения изучаемых морфологических признаков нормальному был использован критерий ШапироУилка. Для анализа межгрупповых различий показателей, не имеющих нормального распределения, применен критерий Краскела-Уоллиса. Критический уровень значимости при проверке статистических гипотез в данном случае принимался равным 0,05. Для попарных сравнений морфологических и функциональных показателей, не имеющих нормального распределения, использован критерий Манна-Уитни. Для контроля ошибки первого рода при множественных попарных сравнениях, использовали поправку Бонферрони; достоверными считали различия при критическом уровне значимости меньше 0,017 (для трех групп). В тексте данные представлены в виде среднее \pm стандартное отклонение.

\section{РЕЗУЛЬТАТЫ}

Основные результаты исследования

Частоты встречаемости генотипов в обследованной выборке составили: FTO*TT - 14\%, FTO*AT-52,6\%, FTO*AA 33,4\%, что соответствуетраспределениюХарди-Вайнберга $\left(X^{2}{ }_{\text {HW }}=1,65 ; \mathrm{p}=0,193\right)$. Частоты встречаемости аллелей составили $40 \%$ и $60 \%$ для FTO*T и FTO*A соответственно.

В таблице 1 представлены морфологические показатели, отражающие накопление и топографию жироотложения в трех подгруппах выборки, сформированных согласно возрасту обследованных.

В таблице 2 представлены значения морфологических показателей, характеризующих накопление жира и его топографию в подгруппах взрослых мужчин, отличающихся образом жизни.

\section{ОБСУЖДЕНИЕ}

Для европейских популяций частота встречаемости А-аллеля составляет от 40 до 70\% [4]. Анализ ассоциаций Т/А-полиморфизма FTO с антропометрическими признаками, характеризующими жироотложение в целом в обследованной группе, выявил связь А-аллеля с повышенным накоплением жира на конечностях. Многие исследования указывают на связь А-аллеля с большими значениями ИМТ и отношения обхвата талии к обхвату бедер - показателям, широко использующимся в скрининговых медицинских исследованиях для оценки риска метаболического синдрома, ожирения и сахарного диабета 2 типа $[2,8]$. Отсутствие ассоциаций с данными признаками в целом для обследованной выборки может быть связано с гетерогенностью обследованной когорты. Поэтому далее была проведена оценка морфологических признаков, характеризующих количество жира и анализ ассоциаций Т/А-полиморфизма FTO с данными показателями в каждой из возрастных подгрупп. В ряду юноши I зрелый - II зрелый возраст увеличиваются все показатели, прямо или косвенно связанные с накоплением 
Таблица 1. Значения некоторых морфологических показателей в трех возрастных подгруппах обследованной выборки

\begin{tabular}{|c|c|c|c|c|}
\hline Признак & Юноши & I зрелый возраст & II зрелый возраст & $\begin{array}{c}\text { Достоверность } \\
\text { различий }\end{array}$ \\
\hline Обхват талии, см & $75,9 \pm 6,5$ & $81,7 \pm 7,6$ & $83,8 \pm 8,4$ & $H=35,1 ; p=0,000$ \\
\hline Обхват груди, см & $91,0 \pm 5,8$ & $93,8 \pm 7,5$ & $95,7 \pm 7,1$ & $H=12,8 ; p=0,002$ \\
\hline $\begin{array}{l}\text { Толщина кожно-жировой } \\
\text { складки под лопаткой, мм }\end{array}$ & $8,9 \pm 3,1$ & $11,2 \pm 4,2$ & $11,9 \pm 4,7$ & $H=23,3 ; p=0,000$ \\
\hline $\begin{array}{l}\text { Толщина кожно-жировой } \\
\text { складки на трицепсе, мм }\end{array}$ & $6,9 \pm 3,1$ & $6,0 \pm 2,8$ & $5,7 \pm 2,7$ & $H=11,0 ; p=0,004$ \\
\hline $\begin{array}{l}\text { Толщина кожно-жировой } \\
\text { складки на животе, мм }\end{array}$ & $10,4 \pm 5,3$ & $12,5 \pm 7,3$ & $14,1 \pm 7,5$ & $H=7,6 ; p=0,021$ \\
\hline ИМТ, $\mathrm{k} г \mathrm{M}^{2}$ & $23,2 \pm 2,6$ & $24,3 \pm 3,9$ & $24,9 \pm 4,4$ & $H=6,3 ; p=0,043$ \\
\hline
\end{tabular}

жира (см. табл. 1). Значения длины и массы тела в данных подгруппах не имеют статистически достоверных различий. В подгруппе юношей (17--21 год) были обнаружены достоверные ассоциации А-аллеля с повышенным жироотложением. Носители генотипов АА и АТ обладают большими значениями толщины кожно-жировых складок на верхних конечностях (кожножировая складка на бицепсе $\mathrm{H}=5,9 ; \mathrm{p}=0,05)$ и на корпусе в области живота $(\mathrm{H}=9,4 ; \mathrm{p}=0,009)$. Отсутствие различий в обхвате талии и толщине кожно-жировых складок на спине у юношей, являющихся носителями альтернативных генотипов FTO, может свидетельствовать о преимущественно абдоминальном жироотложении у носителей А-аллеля при нормальном весе, ИМТ, жировой и мышечной массе тела, которое является одним из индикаторов повышенных рисков развития кардиометаболических заболеваний [1, 2]. Таким образом, в молодом возрасте обнаруживают себя индивидуальные генетические особенности, которые детерминируют преимущественно абдоминальное жироотложение на фоне отсутствия избыточной массы тела. Не было обнаружено ассоциаций Т/А-замены с морфологическими признаками, характеризующими жироотложение в подгруппах мужчин I и II зрелого возраста. Можно отметить лишь некоторое увеличение толщины кожно-жировых складок на ко- нечностях у носителей АА-генотипа, однако тенденция не является достоверной. Вероятно, при достижении зрелого возраста на первый план выходят экзогенные факторы, такие как уровень физической активности, особенности диеты, изменение социально-экономического статуса, которые оказывают наибольшее влияние на накопление жировой массы и могут в значительной мере маскировать индивидуальные генетические особенности [5, 9]. Материалы исследования позволяют проверить данное предположение, так как среди обследованных добровольцев старше 21 года можно выделить несколько подгрупп, резко различающихся особенностями образа жизни.

Анализ морфофункциональных признаков в трех подгруппах мужчин I и II зрелого возраста (22-52 года), отличающихся образом жизни, выявил достоверные различия практически по всем признакам, за исключением ряда костных размеров (длина тела, ширина лодыжки, диаметр таза), которые в наименьшей степени подвержены влиянию экзогенных факторов и сформировались до наступления зрелого возраста (табл. 2). Максимальные различия по комплексу соматических характеристик были обнаружены между вегетарианцами и контрольной подгруппой. Для первых характерны наименьшие значения всех признаков, отражающих развитие жировой и мышечной тканей,

Таблица 2. Значения морфологических показателей в подгруппах мужчин I и II зрелого возрастов, отличающихся образом жизни

\begin{tabular}{|c|c|c|c|c|}
\hline Признак & $\begin{array}{l}\text { Контрольная } \\
\text { группа }\end{array}$ & $\begin{array}{c}\text { Регулярно } \\
\text { занимающиеся } \\
\text { спортом }\end{array}$ & Вегетарианцы & $\begin{array}{c}\text { Достоверность } \\
\text { различий }\end{array}$ \\
\hline Жировая масса тела, кг & $19,9 \pm 5,5$ & $15,7 \pm 5,6$ & $8,6 \pm 3,7$ & $H=59,5 ; p=0,000$ \\
\hline Вес тела, кг & $88,3 \pm 10,4$ & $81,1 \pm 9,8$ & $67,5 \pm 8,3$ & $H=54,9 ; p=0,000$ \\
\hline 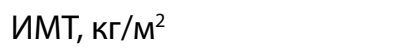 & $28,1 \pm 3,2$ & $25,7 \pm 3,1$ & $21,6 \pm 2,4$ & $H=53,0 ; p=0,000$ \\
\hline $\begin{array}{l}\text { Отношение обхвата талии } \\
\text { к обхвату бедер }\end{array}$ & $0,89 \pm 0,09$ & $0,85 \pm 0,04$ & $0,83 \pm 0,03$ & $H=22,1 ; p=0,000$ \\
\hline
\end{tabular}


а также наихудшие среди обследованных показатели кистевой динамометрии (42,4 $\pm 5,5$ кг), что свидетельствует об относительно низких физических кондициях. Контрольная группа отличается от вегетарианцев и спортсменов наибольшим количеством жировой массы, весом тела, ИМТ и соотношением обхвата талии к обхвату бедер (см. табл. 2), что свидетельствует о преимущественно абдоминальной топографии жироотложения у представителей контрольной группы на фоне его избытка относительно двух других подгрупп. Таким образом, именно представители контрольной группы имеют максимальные риски развития мультифакторных заболеваний, ассоциированных с абдоминальным/висцеральным ожирением [2]. Интересно, что наличие регулярных физических нагрузок средней и высокой интенсивности в зрелом возрасте отражается в достоверном снижении уровня жироотложения по результатам калиперометрии и биоимпедансометрии (у спортсменов и вегетарианцев он практически одинаковый), но не приводит к достоверным различиям в количестве мышечной $(34,7 \pm 3,1$ и 35,8 $\pm 3,3$ кг; $\mathrm{U}=418,5 ; \mathrm{Z}=1,1 ; \mathrm{p}=0,25)$ и тощей массы тела $(68,4 \pm 5,9$ и 65,4 $\pm 5,8$ кг; $U=358,5 ; Z=1,9 ; p=0,05)$, а также силовых показателях согласно результатам кистевой динамометрии $(47,3 \pm 7,2$ и 48,5 $\pm 7,1$ кг; $U=445,5 ; Z=-0,2 ; p=0,84)$ между контрольной и спортивной подгруппами. Полученный результат подтверждается рядом других исследований о влиянии физических нагрузок на ожирение и метаболический синдром $[8,9]$.

Однако внутри данных подгрупп, значительно различающихся по составу тела, присутствуют носители всех трех генотипов FTO. Обследованная выборка позволяет, на наш взгляд, сравнить эффективность различных стратегий по снижению веса и связанных с ним рисков развития мультифакторных заболеваний для носителей альтернативных аллелей FTO. В подгруппе вегетарианцев, характерной особенностью которых являются низкие значения жировой и мышечной массы тела, носители АА-генотипа гена FTO демонстрируют достоверно большие значения признаков, характеризующих эндоморфный компонент состава тела (обхваты, толщина кожно-жировых складок, вес тела, ИMT, жировая масса тела). Функцией FTO является регуляция потребления пищи и энергетического гомеостаза [3]. Показано, что носители А-аллеля потребляют больше пищи и предпочитают более калорийные продукты [1], что приводит к более интенсивному накоплению жира. По всей видимости, эти особенности действуют и при достаточно жестких ограничениях в питании. В подгруппе мужчин, регулярно занимающихся спортом на любительском или профессиональном уровне, достоверных различий между носителями альтернативных генотипов обнаружено не было. Одним из наиболее значительных результатов влияния физических упражнений на изучаемые признаки, на наш взгляд, является снижение количества абдоминального жира, которое происходит у всех обследованных в данной подгруппе мужчин вне зависимости от генотипа FTO. Среднее значение ИМТ в подгруппе

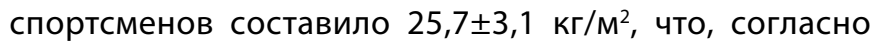
нормам ВО3, соответствует избыточной массе тела. Однако биоимпедансное исследование состава тела данной группы позволяет заключить, что увеличение ИМТ обусловлено хорошим развитием мышечной, а не жировой массы тела. Высокие значения ИМТ часто встречаются у спортсменов и людей, регулярно занимающихся спортом, при этом не сопровождаются негативными изменениями биохимических показателей крови, характерных для метаболических сдвигов при нарушениях веса [10]. В контрольной группе, для которой характерна наибольшая жировая масса тела, был обнаружен ряд достоверных различий соматических характеристик между носителями различных генотипов FTO. Носители А-аллеля обладают большим обхватом талии, а также большим значением индекса обхвата талии к обхвату бедер, что свидетельствует об абдоминальной топографии жироотложения. Отсутствие достоверных различий в толщине кожно-жировых складок на животе на фоне различий вышеуказанных параметров, наводит на мысль о развитии висцерального жироотложения у носителей А-аллеля (FTO*AA и FTO*TA) в данной группе.

\section{Ограничения исследования}

Для уточнения влияния генетических и средовых факторов на склонность к полноте необходимо провести оценку не только общего и подкожного жироотложения, но и висцерального жира. Также представляется необходимым оценить влияние модификаций образа жизни в группе юношей (17-21 год).

\section{ЗАКЛЮЧЕНИЕ}

Сравнение морфологических параметров у носителей альтернативных генотипов в 3 подгруппах, отличающихся образом жизни, позволяет заключить, что А-аллель детерминирует большую склонность к накоплению жира в случаях, когда регулярная физическая активность отсутствует. В целом результаты, полученные для группы взрослых русских мужчин, подтверждают ассоциации А-аллеля FTO с предрасположенностью к набору веса и ожирением. В условиях отсутствия ограничений в диете и регулярных занятиях спортом, у мужчин носителей А-аллеля формируется трункальное абдоминальное жироотложение, которое сопровождается также накоплением висцерального жира. Наиболее действенным способом снижения риска накопления жира, обусловленного А-аллелем FTO, являются регулярные физические нагрузки, которые обеспечивают не только низкое содержание жировой ткани в организме, но и достаточное развитие мышечной массы.

\section{ДОПОЛНИТЕЛЬНАЯ ИНФОРМАЦИЯ}

Источник финансирования. Исследование поддержано грантами РФФИ № 17-26-03004-ОГН и 18-59-94015 МОКНМ_а.

Конфликт интересов. Авторы декларируют отсутствие явных и потенциальных конфликтов интересов, связанных с публикацией настоящей статьи.

Участие авторов. Бондарева Э.А. - сбор материала, обработка данных и написание текста статьи; Задорожная Л.В. - сбор материала; Хомякова И.А. - сбор материала; Все авторы внесли значимый вклад в проведение исследования и подготовку статьи, прочли и одобрили финальную версию статьи перед публикацией. 


\section{СПИСОК ЛИТЕРАТУРЫ | REFERENCES}

1. Hruby A, Hu FB. The Epidemiology of Obesity: A Big Picture. Pharmacoeconomics. 2015;33(7):673-689. doi: 10.1007/s40273-014-0243-x

2. Streng $\mathrm{KW}$, Voors $\mathrm{AA}$, Hillege $\mathrm{HL}$, et al. Waist-to-hip ratio and mortality in heart failure. Eur J Heart Fail. 2018;20(9):1269-1277. doi: 10.1002/ejhf.1244

3. Church C, Moir L, McMurray F, et al. Overexpression of FTO

leads to increased food intake and results in obesity. Nat Genet. 2010;42(12):1086-1092. doi: 10.1038/ng.713

4. Hardy R, Wills AK, Wong A, et al. Life course variations in the associations between FTO and MC4R gene variants and body size. Hum Mol Genet. 2010;19(3):545-552. doi: 10.1093/hmg/ddp504

5. Sheikh AB, Nasrullah A, Haq S, et al. The Interplay of Genetics and Environmental Factors in the Development of Obesity. Cureus. 2017;9(7):e1435. doi: 10.7759/cureus.1435

6. Негашева М.А. Основы антропометрии. - М.: Экон-Информ, 2017. [Negasheva MA. Basis of anthropometry. Moscow: Econ-Inform; 2017. (In Russ.)].
7. Николаев Д.В., Смирнов А.В., Бобринская И.Г., Руднев С.Г. Биоимпедансный анализ состава тела человека - М.: Наука, 2009. [Nikolaev DV, Smirnov AV, Bobrinskaya IG, Rudnev SG. Bioelectric impedance analysis of human body composition. Moscow: Nauka; 2009 (In Russ).]

8. Paley CA, Johnson MI. Abdominal obesity and metabolic syndrome: exercise as medicine? BMC Sports Sci Med Rehabil. 2018;10(1):7. doi: 10.1186/s13102-018-0097-1

9. Davidson $L E$, Hudson R, Kilpatrick K, et al. Effects of Exercise Modality on Insulin Resistance and Functional Limitation in Older Adults. Arch Intern Med. 2009;169(2):122. doi: 10.1001/archinternmed.2008.558

10. Kruschitz R, Wallner-Liebmann S, Hübler K, et al. A measure of obesity: BMI versus subcutaneous fat patterns. Aktuel Ernahrungsmed. 2009;34(03):7. doi: 10.1055/s-0029-1223885

\section{ИНФОРМАЦИЯ ОБ АВТОРАХ [AUTHORS INFO]:}

*Бондарева Эльвира Александровна, к.б.н. [Elvira A. Bondareva, PhD]; адрес: Россия, 125009, Москва, улица Моховая д.11, стр.1 [address: 11/1 Mokhovaya street, 125009 Moscow, Russia]; ORCID: https://orcid.org/0000-0003-3321-7575; eLibrary SPIN: 6732-2072; e-mail: Bondareva.E@gmail.com

Задорожная Людмила Викторовна, к.б.н. [Ludmila V. Zadorozhnaya, PhD];

ORCID: https://orcid.org/0000-0001-9493-6544; eLibrary SPIN: 3075-7754; e-mail: mumla@rambler.ru

Хомякова Ирина Анатольевна, к.б.н. [Irina A. Khomyakova, PhD]; eLibrary SPIN: 2751-1295;

e-mail: irina-khomyakova@yandex.ru

\section{ЦИТИРОВАТЬ:}

Бондарева Э.А., Задорожная Л.В., Хомякова И.А. Т/А-полиморфизм гена FTO и образ жизни ассоциированы с накоплением жира в разных возрастных группах мужчин // Ожирение и метаболизм. - 2019. - Т.16. — №2. — С.49-53. doi: https://doi.org/10.14341/omet9798

\section{TO CITE THIS ARTICLE:}

Bondareva EA, Zadorozhnaya LV, Khomyakova IA. T/A polymorphism of the FTO gene and lifestyle are associated with fat accumulation in different age groups of men. Obesity and metabolism. 2019;16(2):49-53.

doi: https://doi.org/10.14341/omet9798 